\title{
Periodontal Manifestations in Vertical Root Fractured Teeth
}

\author{
Nina Shenoy ${ }^{10}$ Arvind Shenoy ${ }^{2}$ \\ ${ }^{1}$ Department of Periodontics, AB Shetty Memorial Institute of Dental \\ Sciences (ABSMIDS), Nitte (Deemed to be University), Mangalore, \\ Karnataka, India \\ 2 Department of Conservative Dentistry and Endodontics, Bapuji \\ Dental College and Hospital, Davangere, Karnataka, India \\ J Health Allied Sci ${ }^{\mathrm{NU}} 2022 ; 12: 230-234$.
}

\begin{abstract}
Address for correspondence Nina Shenoy, MDS, Department of Periodontics, AB Shetty Memorial Institute of Dental Sciences (ABSMIDS), Nitte (Deemed to be University), Mangalore 575018, Karnataka, India

(e-mail: ninashenoy@gmail.com; drninavijaykumar@nitte.edu.in).
\end{abstract}

\begin{abstract}
Keywords

- VRF

- cracked tooth

- probing depth

- bruxism

- RCT

- periodontal abscess

Vertical root fractures are more commonly encountered following endodontic treatment and in teeth without endodontic treatment, with habits like bruxism and eating coarse, hard food. The teeth most predisposed to fracture are the premolars of the maxilla and mandible, the mesial roots and mesiobuccal roots of the mandibular molars, maxillary molars and the mandibular incisors. Timely identification of cracked teeth and fractures is the key since it permits a conservative and preventive approach. Delay in diagnosis and treatment will result in the involvement of the underlying periodontium, causing periodontal pockets, abscess formation, and bone loss, thereby further complicating the outcome. Appropriate diagnosis, education, and counseling of the patient by the dentist and coronal restoration following root canal treatment are mandatory to prevent the loss of teeth in patients. The prognosis of multirooted teeth is more favorable. Affected single-rooted teeth may, however, require immediate extraction. MEDLINE database and Scopus search (www.scopus.com) were performed using the key words "vertical root fracture" or "Iongitudinal root fracture." Text book chapters were manually checked.
\end{abstract}

\section{Introduction}

According to the American Association of Endodontists (AAE), five categories of cracks are craze lines, fractured cusp, cracked tooth, split tooth, and vertical root fracture (VRF). ${ }^{1}$ Sharp pain during mastication, sensitivity to cold and ache or pain on the release of bite force, is characteristic of cracked tooth syndrome. ${ }^{2}$ Advanced cracks in teeth are associated with deep probing depths of $>6 \mathrm{~mm}$, which is an important element in the prognosis of the tooth. Intact teeth are associated with $65 \%$ prevalence of cracks. $^{3}$ As per the Glossary of Endodontic Terms, AAEs, a VRF is an incom- plete root fracture that may occur buccolingually or mesiodistally; it may cause periodontal defect(s) or sinus tracts and may be radiographically evident. It can be either complete or incomplete and confined to the root. ${ }^{4,5}$

AVRF is a complex clinical scenario that mostly occurs due to the production of lateral wedging forces during compaction of gutta-percha for obturation or post-placement, which can induce stresses and strains during root canal treatment (RCT) ${ }^{6-8}$

Additional masticatory forces in patients with chronic parafunctional habits can lead to the extraction of the affected tooth. It is also be detected in intact teeth in patients published online January 18,2022
DOI https://doi.org/ 10.1055/s-0041-1741416 ISSN 2582-4287.

\footnotetext{
(C) 2022. Nitte (Deemed to be University). All rights reserved. This is an open access article published by Thieme under the terms of the Creative Commons Attribution-NonDerivative-NonCommercial-License, permitting copying and reproduction so long as the original work is given appropriate credit. Contents may not be used for commercial purposes, or adapted, remixed, transformed or built upon. (https://creativecommons.org/ licenses/by-nc-nd/4.0/) Thieme Medical and Scientific Publishers Pvt. Ltd., A-12, 2nd Floor, Sector 2, Noida-201301 UP, India
} 
with chronic trauma from occlusion such as bruxism, clenching, eating hard foods such as nuts, and thermal cycling., ${ }^{3,9}$

The teeth most predisposed to fracture are the premolars of the maxilla and mandible, the mandibular incisors, mesial root, mesiobuccal roots of the mandibular molars, and maxillary molars. ${ }^{10}$

This type of fracture is usually diagnosed by secondary symptoms that develop following the primary treatment, often when the coronal restoration has already been completed. The fracture line itself is often not directly visible, and therefore, the history, clinical, and radiographic signs and symptoms are important factors that can lead to a correct diagnosis. It is vital to pay attention to the patient's chief complaints, a thorough clinical examination and proper scrutiny of periapical and bitewing radiographs. ${ }^{11}$ Hence, in more advanced cases, it requires an interdisciplinary approach with an endodontist and periodontist to rule out similar appearing endodontic-periodontal lesions.

\section{Etiology}

Because of the devastating effects and the lack of treatment modalities for VRF, it is very critical to identify the etiology. Many such etiologies have been suggested, they can be categorized as predisposing and iatrogenic factors (-Table 1).

\section{Clinical Manifestation}

\section{Early Manifestation}

The probability of a VRF should be borne in mind if a wellcompleted root canal-treated tooth does not resolve after completion. When "pain on biting" complemented with a "bad taste" is present in a root canal-treated tooth, a VRF can be suspected. ${ }^{12}$

Commonly, patients complain they felt a jolt of pain on biting hard food like nuts and may state that "since then, the

Table 1 Predisposing and latrogenic factors of VRF

\begin{tabular}{|l|l|}
\hline Predisposing factors & Latrogenic factors \\
\hline $\begin{array}{l}\text { Excessive occlusal loads or } \\
\text { intensity of such loads }\end{array}$ & $\begin{array}{l}\text { Root canal treatment } \\
\text { procedures }\end{array}$ \\
\hline Trauma, bruxism, and clenching & Intraradicular dowels \\
\hline $\begin{array}{l}\text { Previous cracks in dentin } \\
\text { Caries }\end{array}$ & $\begin{array}{l}\text { Wedging forces of } \\
\text { post placement and } \\
\text { obturation }\end{array}$ \\
\hline $\begin{array}{l}\text { Anatomy of the roots- } \\
\text { mesiodistal and bucco-lingual } \\
\text { dimension }\end{array}$ & \\
\hline $\begin{array}{l}\text { Oversized post preparation } \\
\text { leading to a weakened tooth } \\
\text { structure, excessive pressure } \\
\text { during cementation of posts }\end{array}$ & \\
\hline $\begin{array}{l}\text { Obturation-related stress and } \\
\text { strain in the roots }\end{array}$ & \\
\hline Post or pin corrosion & \\
\hline
\end{tabular}

tooth felt different." In the initial stages, the patient may notice a mild discomfort when biting or chewing, sensitivity, or pain on lateral percussion. In a study evaluating root canal treated, vertically fractured teeth, Tamse et al detected that $50 \%$ or more patients reported some kind of dull ache and pressure on biting. Chronic inflammatory lesion in the area was reported in $35 \%$ of patients in the form of an abscess. ${ }^{13}$

If the fracture and subsequent infection are allowed to progress, a deep narrow probing will be evident along the fracture location, swelling often occurs in the attached gingiva, and a sinus tract may be located more coronally, compared with an apical location of a sinus tract in the case of chronic periapical abscess (-Figs. 1 and 2). The point of sinus tract drainage is called a stoma or parulis. This mostly indicates the presence of necrotic pulp and chronic periapical abscess. These signs and symptoms have to be differentiated from nonhealing RCT that are very similar. ${ }^{2}$

\section{Late Manifestation}

As the fracture progresses, the periodontal probing pattern that was narrow and deep later becomes wider and deeper at the fracture location. In well-established chronic cases, the bone destruction is extensive, the root fragments may

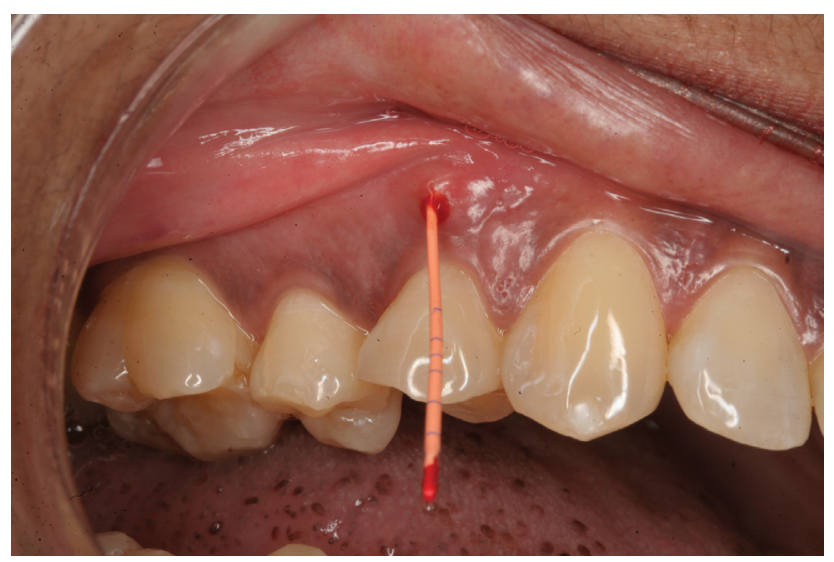

Fig. 1 Depicting abscess located on the attached gingiva and sinus tracing with gutta-percha.

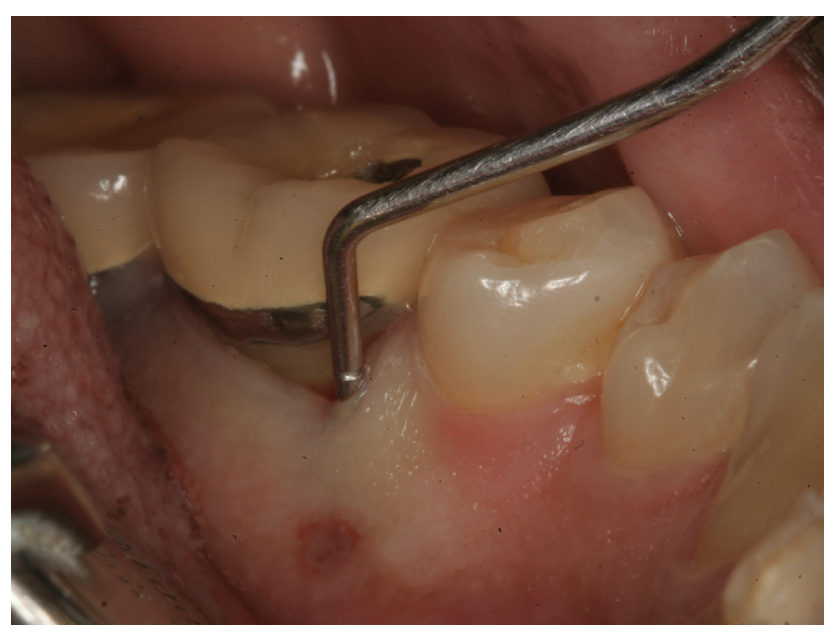

Fig. 2 Depicting deep narrow periodontal probing on a tooth with a sinus tract coronally located on the attached gingiva. 
separate, and radiographically an objective root fracture is detected. In such cases, the prognosis is poor and tooth is indicated for extraction. ${ }^{2}$

Of $35 \%$ of patients with a sinus tract, $24 \%$ presented with deep osseous defects buccally, and in $13-42 \%$ patients, a sinus tract was observed by Tamse et al on the evaluation of VRFs in endodontically treated teeth. The sinus tract location was typically closer to the marginal gingiva, as in contrast to failed RCTs in which sinus tracts often are in an apical location. Many patients examined had buccal and lingual/palatal sinus tracts, at both aspects. This is a characteristic and typical sign for a VRF. ${ }^{13}$

Implications: Avenue for bacterial ingress leading to

- Pulpal pathosis

- Periodontal pathosis

- Failed RCT

\section{Periodontal Manifestations}

Complete or incomplete VRFs extend to the supporting periodontium. The resultant soft tissue ingrowth into the fracture space intensifies the separation of the root segments. Bacteria, debris, and foreign material make a pathway through the gingival sulcus into the fracture zone while communicating with the oral cavity. This invasion results in an inflammatory process, resulting in the destruction of the supporting periodontium and granulation tissue formation, thereby a rapid progression of the bony defect in an apical and interproximal direction. Periodontal breakdown and bone resorption are quicker in premolars, i.e., in premolars of the maxilla where the buccal cortical plate is thin and the mesial roots of the mandibular molars, the most prone to fracture. Most commonly dehiscence-type bone resorption in the buccal cortical plate develops in teeth associated with a periodontal abscess. ${ }^{6}$ When the fracture does not involve the coronal or apical aspect of the root, fenestration-type bone defects can be observed on the buccal aspect. ${ }^{14}$

\section{Probing Pattern}

A deep narrow isolated probing pattern adjacent to the fracture site is a common feature of VRF teeth. Bilateral probing patterns may be visible in a through and through fracture. The probing pattern should be differentiated in VRF that is narrow/wide but localized compared with a generalized wider consistent conical probing pattern in periodontitis. ${ }^{15} \mathrm{~A}$ sudden deep dip of the periodontal probe in an isolated location around the circumference of the tooth in the presence of otherwise normal attachment usually indicates a fractured $\operatorname{root}$ (-Fig.2). A characteristic indication of a fracture would be two deep probing depths on opposite sides of the infection. Teeth with large restorations may necessitate complete removal of the restoration before deep interproximal periodontal probing of molar teeth with fractures mesiodistally. ${ }^{12}$

\section{Bone Resorption Pattern}

Periodontal breakdown and bone resorption are rapid in premolars where the buccal cortical plate is thin. ${ }^{4}$ An initial dehiscence-type defect forms in the buccal plate that resorbs apicocoronally. As the fracture advances, the bone defect becomes wide with extension inter-proximally and laterally. This is best observed by the reflection of a full-thickness periodontal flap and thorough debridement.

\section{Diagnosis}

The diagnosis of VRFs should carefully take into consideration the patient's chief complaint, a thorough dental history, and detailed clinical examination. After which, based on the location of the fracture and periodontal involvement, the prognosis assessment and steps in the management must be considered. Since there is no single specific indicator of VRF, a combination of all aspects, clinical, and radiographic analysis is mandatory in the diagnosis.

\section{Clinical Examination}

- Patient history-Patients may convey a long history of undiagnosed pain or sensitivity on related or adjacent to a given tooth, despite several clinical and radiographical examinations. Sensitivity and discomfort while chewing are also common complaints.

- Hard tissue examination-A bite test using a Tooth Slooth (Professional Results, Laguna Niguel, CA, United States) or a similar device can be used to detect a cracked tooth. ${ }^{2}$ When the patient bites down on the Tooth Slooth, it will reproduce the sensation of a sharp pain of the chief complaint or pressure upon release. ${ }^{16}$

- Soft tissue and gingival examination-Visual examination of gingival swelling and sinus tract formation is a crucial step. Fistula tracking is done by inserting a semi-rigid radiopaque material into the sinus track until resistance is met. Taking a second radiograph with the insertion of a material such as gutta-percha cones into the sinus tract will indicate the course of the sinus tract and the origin of the lesion (-Fig. 1). ${ }^{15,17}$

- Periodontal probing-A periodontal probe is a mandatory requirement in the armamentarium. The probing depth must be carefully evaluated around the involved and adjacent teeth.

- Staining-Methylene blue or tincture of iodine dyes can help detect a fracture line. A cotton pellet soaked with methylene blue dye is swabbed on the dried occlusal surface of the tooth. The patient is asked to bite down an object like a stick, along with lateral jaw movements. This enables the dye penetration into the fracture area. Subsequently, the dye is rinsed from the tooth surfaces and a distinct fracture line is visualized with magnifying loops or microscopic examination. ${ }^{17}$

- Pulp testing-Pulp testing is carried out to determine the pulpal innervation of the affected tooth.

- Magnification and transillumination-Magnification of the area with loupes or an operating microscope can be of value when looking for a crack. Large intracoronal restorations need to be removed prior to transillumination. If 
the tooth does not have an extensive intracoronal restoration, fiber optic transillumination in a dark room will penetrate the tooth structure, leaving the area beyond the crack dark, thus disclosing the crack. ${ }^{2}$

- Radiographs-The root canal-treated tooth may appear normal radiographically. Often, periapical radiographs at different angulations may be necessary to verify the existence of a fracture. The commonly occurring radiographic features of VRFs are the "halo" appearance. There may be a radiolucency in one or both sides of the root, radiolucency along the root laterally, or angular radiolucency from the bone crest ending by the root side. Space besides a post or root filling may also be detected. ${ }^{18-20}$

- Exploratory surgical assessment-Surgical full-thickness flap reflection may eventually be required to visibly confirm the presence of a root fracture along with the type of bone loss. This will provide a confirmatory diagnosis of VRF to the clinician. ${ }^{14}$

- Cone-beam computed tomography (CBCT)-Although CBCT has been used and there are some cases where it was helpful, the main problem with it is the masking of the fracture line by the obturating material or posts making it an unreliable tool. With the current CBCT devices, unseparated fracture width may be too small and undetectable. The smallest voxel size of approximately $0.075 \mathrm{~mm}$ is currently available for a CBCT device. Hence, CBCT imaging would not be able to visualize a root fracture of greater than $0.15 \mathrm{~mm}$ width. ${ }^{2}$ The literature from meta-analysis and systematic reviews conclude that the use of CBCT in the detection of VRF as a diagnostic tool may be unreliable. $^{21-23}$

\section{Prognosis and Management}

The severity, position of the crack, and discomfort experienced by the patient determine the prognosis and management. When the crack is minute without pulpal involvement, resins, inlays, or crowns may be used to restore the tooth in a conservative manner. ${ }^{24} \mathrm{RCT}$ is mandatory in patients with worsening chronic symptoms such as tooth hypersensitivity, pulpal involvement periodontal abscess, and deep probing depths, prior to completing the coronal restoration. Early detection of cracked and fractured teeth can enable the establishment of conservative preventive strategies to avoid complications.

Single-rooted teeth generally have a poor prognosis when there is advanced involvement. Molars, on the contrary, can be salvaged by treatment with root resection and hemisection and coronal restoration. Persistence of symptoms, severe destruction of the underlying periodontium, and loss of attachment can hamper the prognosis and lead to the extraction of the tooth. ${ }^{3,14,25}$ In patients with suspected VRF with severe periodontal destruction, tooth or root extraction is recommended at the earliest. Any delay may possibly compromise the replacement with an endosseous implant. Thus, all precautionary and diagnostic measures are necessary at an early stage. Several efforts at repairing fractures with a variety of restorative materials like cyanoacrylates have been reported in the literature; yet, none of the outcomes of these treatment options is regarded as a dependable long-term solution. ${ }^{2,5}$

\section{Conclusion}

VRFs are challenging and confusing to detect clinically. Various tests along with the patient's signs, symptoms, and history must be meticulously considered to arrive at a confirmatory diagnosis. It is important to detect the causative factor/s to determine the prognosis of such teeth and the best treatment option. Hence, early detection is vital and can be managed conservatively since the management depends on the extent and severity of the lesion.

Heroic attempts to treat such teeth with conservative approaches in most cases may not be possible. Following root canal treatment, a coronal restoration is mandatory. Singlerooted teeth generally have a poor prognosis, whereas it may be possible to save multirooted teeth. Progress into the underlying periodontium with severe bone loss can hamper the prognosis of such teeth and lead to extraction.

Conflict of Interest

None declared.

Acknowledgment

None.

\section{References}

1 Rivera EM, Walton RE. Cracking the cracked tooth code: detection and treatment of various longitudinal tooth fractures. Am Assoc Endodontists Colleagues for Excellence News Lett 2008;2:1-9

2 Berman LH. Cracks and fractures. In: Berman LH, Hargreaves KM, eds. Cohen's Pathways of the Pulp. MO: Elsevier Health Sciences; 2020:793-817

3 Kang SH, Kim BS, Kim Y. Cracked teeth: distribution, characteristics, and survival after root canal treatment. J Endod 2016;42 (04):557-562

4 Walton RE. Vertical root fracture: factors related to identification. J Am Dent Assoc 2017;148(02):100-105

5 Matthews DC, Tabesh M. Detection of localized tooth-related factors that predispose to periodontal infections. Periodontol 2000 2004;34:136-150

6 Liao WC, Tsai YL, Wang CY, et al. Clinical and radiographic characteristics of vertical root fractures in endodontically and nonendodontically treated teeth. J Endod 2017;43(05): 687-693

7 Schwarz S, Lohbauer U, Petschelt A, Pelka M. Vertical root fractures in crowned teeth: a report of 32 cases. Quintessence Int 2012;43(01):37-43

8 Barreto MS, Moraes RdoA, Rosa RA, Moreira CH, Só MV, Bier CA. Vertical root fractures and dentin defects: effects of root canal preparation, filling, and mechanical cycling. J Endod 2012;38(08): 1135-1139

9 Qiao F, Chen M, Hu X, et al. Cracked teeth and poor oral masticatory habits: a matched case-control study in China. J Endod 2017; 43(06):885-889

10 Hsiao LT, Ho JC, Huang CF, Hung WC, Chang CW. Analysis of clinical associated factors of vertical root fracture cases found in endodontic surgery. J Dent Sci 2020;15(02):200-206 
11 Haueisen H, Gärtner K, Kaiser L, Trohorsch D, Heidemann D. Vertical root fracture: prevalence, etiology, and diagnosis. Quintessence Int 2013;44(07):467-474

12 Moule AJ, Kahler B. Diagnosis and management of teeth with vertical root fractures. Aust Dent J 1999;44(02):75-87

13 Tamse A, Fuss Z, Lustig J, Kaplavi J. An evaluation of endodontically treated vertically fractured teeth. J Endod 1999;25(07):506-508

14 Tamse A. Vertical root fractures in endodontically treated teeth: diagnostic signs and clinical management. Endod Topics 2006;13 (01):84-94

15 Shenoy N, Shenoy A. Endo-perio lesions: diagnosis and clinical considerations. Indian J Dent Res 2010;21(04):579-585

16 Banerji S, Mehta SB, Millar BJ. Cracked tooth syndrome. Part 1: aetiology and diagnosis. Br Dent J 2010;208(10):459-463

17 Rotstein I, Simon JH. Diagnosis, prognosis and decision-making in the treatment of combined periodontal-endodontic lesions. Periodontol 2000 2004;34:165-203

18 Tsesis I, Rosen E, Tamse A, Taschieri S, Kfir A. Diagnosis of vertical root fractures in endodontically treated teeth based on clinical and radiographic indices: a systematic review. J Endod 2010;36 (09):1455-1458

19 Cohen S, Blanco L, Berman L. Vertical root fractures: clinical and radiographic diagnosis. J Am Dent Assoc 2003;134(04):434-441
20 See WK, Ho JC, Huang CF, Hung WC, Chang CW. The association between clinical diagnostic factors and the prevalence of vertical root fracture in endodontic surgery. J Formos Med Assoc 2019; 118(03):713-720

21 Neves FS, Freitas DQ Campos PS, Ekestubbe A, Lofthag-Hansen S. Evaluation of cone-beam computed tomography in the diagnosis of vertical root fractures: the influence of imaging modes and root canal materials. J Endod 2014;40(10):1530-1536

22 da Silveira PF, Vizzotto MB, Liedke GS, da Silveira HL, Montagner F, da Silveira HE. Detection of vertical root fractures by conventional radiographic examination and cone beam computed tomography - an in vitro analysis. Dent Traumatol 2013;29 (01):41-46

23 PradeepKumar AR, Shemesh H, Nivedhitha MS, et al. Diagnosis of vertical root fractures by cone-beam computed tomography in root-filled teeth with confirmation by direct visualization: a systematic review and meta-analysis. J Endod 2021;47(08): 1198-1214

24 Lynch CD, McConnell RJ. The cracked tooth syndrome. J Can Dent Assoc 2002;68(08):470-475

25 Lubisich EB, Hilton TJ, Ferracane JNorthwest Precedent. Cracked teeth: a review of the literature. J Esthet Restor Dent 2010;22(03): 158-167 